\title{
A LION AND HIS PREY
}

By E. P. GeE

It was two o'clock in the afternoon in the Serengeti National Park, Tanganyika. Two magnificent maned lions were in front of us, some Thomson's gazelles were grazing around, while sandgrouse and Egyptian geese were drinking at a pool nearby.

We drove as close as possible to the nearest lion, went all round him and came to a stop facing in the direction in which he was intently staring. He continued to stare straight ahead. I followed the direction of his stare and observed a herd of zebra about a quarter of a mile away, all looking in our direction. One of the zebra was slightly away from the rest, to the left.

Presently the lion started off at a steady walk. We started off too. The lion and our Land-Rover went together, keeping abreast, only about fifty feet apart, across the burnt-up grass, over a dried-up stream bed, across the short yellow grass. The lion never so much as glanced at us as we kept alongside him. I kept wondering if something was going to happen ...

Suddenly the lion stopped dead. Slowly his mane and the hair all down his back stood erect as he fixed his terrible stare on the wretched zebra in front. His black-tufted tail was raised aloft and swished ominously from side to side. An unforgettable sight: the cat and the bird scene on the lawn magnified a thousand times. The poor zebra, cars cocked forward, timidly returned the stare, having observed the lion all the time across the open country.

Then the lion resumed his walk. He never once crouched, and made no use at all of ground cover which was available in the form of scattered thorn bushes and acacia trees. Dead straight across the open he went. Now he was doing a fast trot. Later he broke into a steady canter. My African driver kept at fifty fect distance from him.

At this point I noticed that the sky had darkened and that an occasional drop of rain was falling. The sounds of thunder rumbled in the distance: as though the heavens above were enlivening the grim spectacle with a dramatic accompaniment of the clements.

The grass was now longer. The pace had suddenly increased. The lion was off at a gallop after the zebra. The zebra was at last attempting to escape, half-heartedly, it seemed. The struggle for existence was madly on.

- Soon the lion was racing alongside his quarry. Then he 


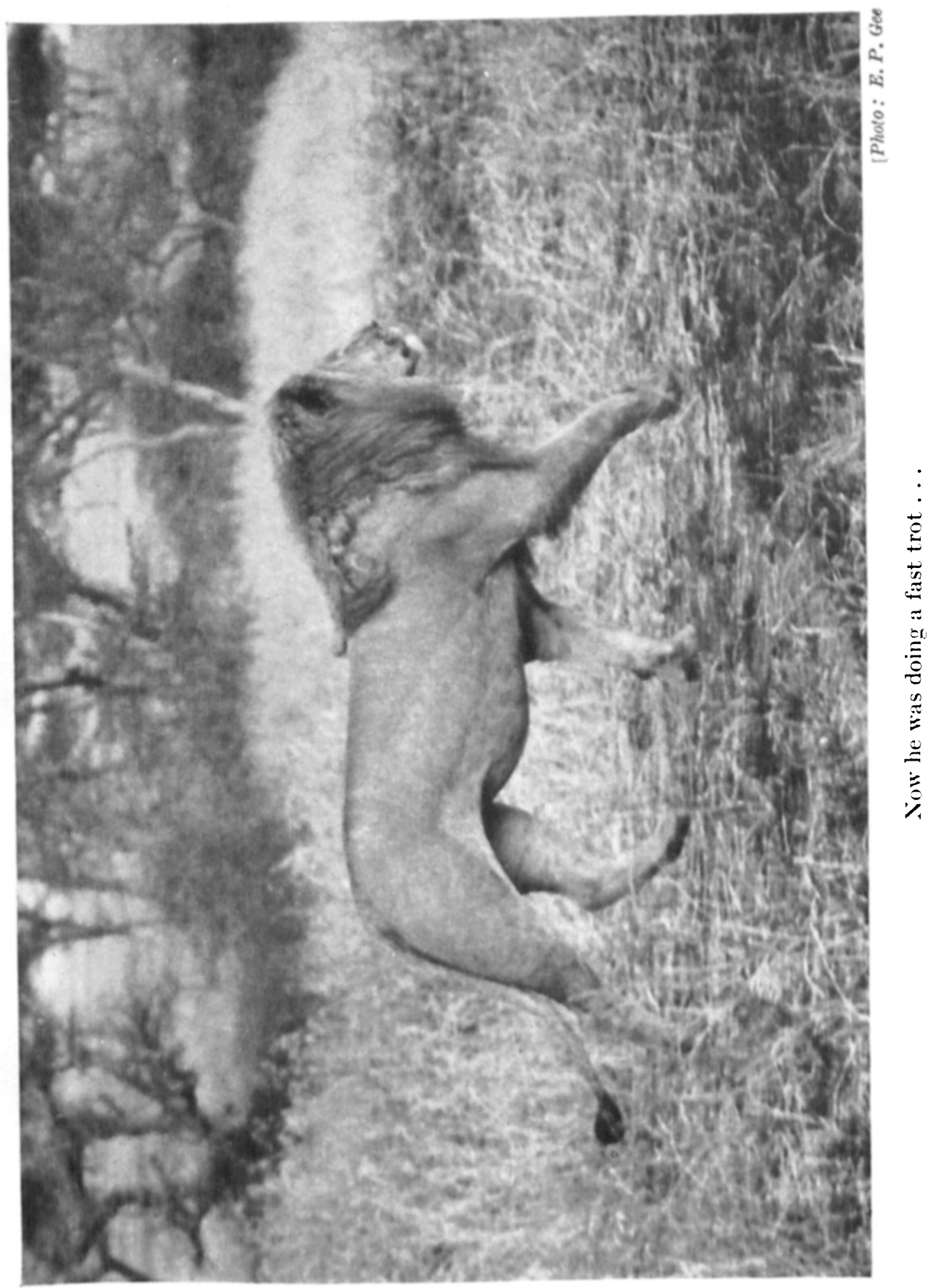


sprang. Both animals crashed, to disappear in the long grass. A cloud of dust arose.

I was spectator at an awe-inspiring scene in which the stern law of nature had been enforced. Here the most unwitting member of the herd of handsome zebra had succumbed to the power of the predator : a commonplace fulfilment of the natural law of tooth and claw, predator and prey, survival of the fittestwithout which the animal world could not survive in its rich and interesting variety. I felt I was an intruder and a witness of something that I should not have seen, something that usually happens under cover of darkness. How often we see the remains of some dead animal by daylight, never realizing the grim drama and tragedy which must have been enacted the night before!

Recovering from the impact of the spectacle, we drove hurriedly up to the scene of the kill, and stopped the vehicle a few yards from the dying zebra. The mane and part of the back of the lion were just visible as he lay on the ground holding down the zebra's neck in his mighty jaws to strangle it. After a few minutes he stood on top of his victim, twisted up its. neck to satisfy himself there was no life left, and then lay down in the grass only a few feet away from the dead zebra and us.

It was now 2.30 p.m. and raining; and for the first time it occurred to me that I was dusty, hungry and thirsty. Within a few minutes we were at the safari lodge and I was thanking the Park Warden for the very fine reception I had received.

Mr. E. P. Gec will be well known to our readers both as a most faithful correspondent from India and for his knowledge and care of the great Indian rhinoceros in the Kaziranga Wild Life Sanctuary, Assam. Recently he has been visiting East Africa, and has contributed most interesting reports to the Indian newspaper The Statesman. Permission to extract the above article from these reports is gratefully acknowledged.-Ed. 